\title{
Perception of Individualized Care and Satisfaction with Nursing Care of Women Who Give Birth by Cesarean Section
}

\author{
Ezgi Yildiz ${ }^{1(\underline{I D})}$, Nilufer Tugut ${ }^{2(\underline{I})}$ \\ ${ }^{1}$ Department of Nursing, Sivas Cumhuriyet University Susehri School of Health, Sivas, Turkey, \\ ${ }^{2}$ Department of Gynecology and Obstetrics Nursing, Sivas Cumhuriyet University Faculty of Health Sciences, Sivas, Turkey, \\ Copyright@ Author(s) - Available online at https://dergipark.org.tr/en/pub/mbsjohs \\ Content of this journal is licensed under a Creative Commons Attribution-NonCommercial 4.0 International \\ License,
}

Received: 08 August2021, Accepted: 24 November 2021, Published online: 30 April 2021

(C) Ordu University Institute of Health Sciences, Turkey, 2021

\begin{abstract}
Objective: This descriptive cross-sectional study aims to determine the perception of individualized care and satisfaction with the nursing of women who underwent cesarean section.

Methods: The population of this study consists of women undergoing cesarean section in a university hospital between 15 August and 15 December $2018(\mathrm{~N}=260)$. The sample consists of 156 women giving birth by cesarean section who have agreed to participate in this study. The data have been collected by using the Personal Information Form and the Individualized Care Scale (ICS) and the Newcastle Satisfaction with Nursing Scale (NSNS).

Results: It has been found that the women who gave birth by cesarean section have good ICSA (3.50 \pm 0.99$)$, ICSB (3.82 \pm 1.18$)$, and NSNS (70.53 \pm 16.27$)$ mean scores. There is a significant, positive, and moderate relationship between the ICS and NSNS scores. It has been found that there is a statistically significant difference between the place of residence and the level of satisfaction with nursing. It has been determined that the women whose income is higher than their expenses are more satisfied with nursing care, and their individualized care perception is higher.

Conclusion: It has been determined that women who gave birth by cesarean section have a good level of individualized care perception and nursing satisfaction. It has been found that women's satisfaction with nursing increases.
\end{abstract}

Key words: Individualized care; satisfaction with nursing care; cesarean section

Suggested Citation: Yildiz E, Tugut N. Perception of Individualized Care and Satisfaction with Nursing Care of Women who Give Birth by Cesarean Section. Mid Blac Sea Journal of Health Sci, 2021;7(3):366-377.

\section{Address for correspondence/reprints:}

Ezgi Yildiz

Telephone number: +90 (543) 4236118

E-mail: ezgiyildiz58@ hotmail.com

\section{Introduction}

Cesarean section, which is a surgical intervention, should be preferred in case a condition threatens the health of both the woman and the baby. In cesarean section, maternal mortality and morbidity rate is higher than it is in vaginal delivery. Cesarean delivery is increasing all over the world (1-3). According to the data released by Turkey's Ministry of Health and the Organization for Economic Cooperation and Development (OECD), Turkey takes the first place 
among the countries in the world where cesarean section is performed most (4).

Regardless of the mode of delivery, the birth and postpartum period is the most sensitive period in a woman's life because in this period, the mother experiences intense physiological and psychological changes and possible health problems (5). Health problems are widespread in the postpartum period, especially in the first days, and most of these problems are likely to persist for up to six and eight weeks or even a year (6). The postpartum is a period when mother and baby need nursing care a lot. During this period, nurses, who are directly responsible for care, assume significant responsibilities in preventing problems observed in the mother and baby (7). Especially the risks of cesarean section on maternal and infant health make the individualized nursing care given to women who have undergone cesarean section more important, because it is only possible to talk about quality care when an individual's needs and desires are met. Individualized care is provided to improve the quality of care, to determine the direction of care, to establish clinical guidance, to create positive patient outcomes and to maximize all these.

The more an individual's personal characteristics, values, beliefs, and cultural characteristics are taken into account in the provision of care, the more the individuality of the care increases (8). Providing and maintaining individuality in the provision of care is possible as the problems determined are solved by evaluating all the dimensions of an individual, implementing interventions specific to the individual and allowing the patient to participate in care decisions. Individualized care, offered by taking into account characteristics unique to an individual, can yield positive results such as the improvement and functioning of personal health, quality care, autonomy, provision of satisfaction, improvement of the person's use of autonomy, and increase in the quality of life of individuals.

Individualized care is thought to be related to the patient's satisfaction with nursing care. Given the diversity of health problems after cesarean section, the wide variety of care and needs, and the wide variety of perspectives and expectations of women receiving health services, the importance of individualized care planned through cooperation between the patient and nurse, and of patient satisfaction comes to the fore (9). The basis of patient satisfaction is the cooperation between the patient and nurse (10).

Measurement of patient satisfaction related to nursing care plays an important role in determining the patient's needs, planning appropriate nursing interventions, evaluating the results and making changes in the provision of care according to their preferences $(11,12)$. Providing nursing care in line with the needs of the mother and family until the postpartum period is over is very important for the healthy management of this process. Therefore, this study was conducted to determine how women who underwent cesarean section perceived individualized care and whether they were satisfied with the nursing care they were given.

\section{Methods}

\section{Type and Place of the Study}

This descriptive cross-sectional study was conducted in the obstetrics and gynecology service with a capacity of 31 beds where 11 nurses and 2 midwives worked. Each nurse looks after an average of $10-15$ patients per shift.

\section{Study Population and Sample}

The population of the study consisted of women who were hospitalized in the gynecology and obstetrics service of a university hospital between August 15, 2018, and December 15, $2018(\mathrm{~N}=260)$. In the present study, no sampling method was implemented. Of the women in the study population, 156 who received inpatient care in this clinic between the aforementioned dates, who could answer questions independently when they were discharged from the hospital, who did not have psychiatric problems, and who volunteered to participate in the study constituted the study sample.

\section{Measures}

The following three forms were used to collect the study data: Personal Information Form, Individualized Care Scale (ICS) and Newcastle Satisfaction with Nursing Scale (NSNS).

\section{Personal Information Form}

The form prepared by the researchers based on the pertinent literature includes eight closed-ended questions on the patient's age, income level, education status, place of residence, health insurance, employment status, the number of hospitalizations, and the number of cesarean deliveries $(1,13)$.

\section{Individualized Care Scale (ICS)}

The scale developed by Suhonen et al. to evaluate individualized care from the patients' point of view was adapted to Turkish by Acaroglu et al. $(14,15)$. The ICS has two parts each containing 17 items: the ICS-A used to assess the patient's awareness of 
nursing interventions, the ICS-B used to assess the patient's perception of individuality in the care given to her. The Cronbach's alpha coefficient of the ICS$\mathrm{A}$ and ICS-B was determined as 0.92 and 0.93 , respectively. Responses given to the items are rated on a 5-point Likert type scale ranging from 1 to 5 . The scores of the ICS-A and ICS-B are calculated by summing the item scores obtained from their subscales and dividing them by the number of the items for each subscale separately. Therefore, the mean score for each subscale also varies between 1 and 5. The higher the score obtained from the ICS-A is the more individualized the nursing interventions provided for the individual are. Similarly, the higher the score obtained from the ICS-B is the higher the level of the patient's perception of individuality for the care given to her. In the present study, the Cronbach' alpha coefficient for the ICS-A and ICS-B was 0.94 and 0.95 respectively.

\section{Newcastle Satisfaction with Nursing Scale} (NSNS)

The NSNS developed by Thomas et al. to determine patients' satisfaction with nursing care was by Akin and Erdogan $(11,16)$. The scale consists of 19 items whose responses are rated on a 5-point Likert-type scale ranging from 1 to 5 (Not at all satisfied $=1$, Barely satisfied $=2$, Quite satisfied $=3$, very satisfied $=4$, completely satisfied $=5$ ). The minimum and maximum possible scores to be obtained from the scale are 19 and 95 respectively. The higher the total score obtained from the scale is the more satisfied the patient with the nursing care is. The Cronbach's alpha coefficient of the scale was 0.96 in Akin and Erdogan's study and 0.97 in the present study.

\section{Implementation of the Study and Ethical Issues}

To conduct the study, Ethics Committee approval from Cumhuriyet University Non-Interventional Clinical Research Ethics Committee, (Decision No: 2018-04 / 02) and written permission from the institution where the study was to be conducted were obtained. The patients who met the inclusion criteria and volunteered to participate in the study were informed about the study and then the Informed Consent Form was administered to them to obtain their consent to participate in the study. A suitable environment (quiet, calm, etc.) was established for patients whose discharge procedures were initiated. After they were given information on the data collection tools, the tools were administered to them and they were asked to fill in the forms, which took approximately 10 minutes.
Statistical analysis

The data obtained were analyzed using the SPSS 23.0 software program. In the analysis, the numeric data (women's education level, the number of cesarean deliveries, place of residence, etc.) were given as frequency distribution, and the data obtained by measurement (perceived individualized care and the level of satisfaction with the nursing care) were given as arithmetic mean and standard deviation. In the analysis of the normally distributed data, the t-test was used for two groups and the ANOVA was used for more than two groups. When the mean scores of independent groups not showing normal distribution were compared, Mann Whitney-U test was used for the two groups and if the number of the independent groups was more than two, Kruskal Wallis analysis was used. Spearman correlation analysis was used to determine the direction and level of the relationship between the scales, and the margin of error was taken as 0.05 .

\section{Results}

In Table 1, the descriptive characteristics of the women who gave birth by cesarean section are given. Their mean age was $30.49 \pm 6.46$ years. Of them, $44.2 \%$ were primary school graduates, $60.3 \%$ lived in a city, $78.8 \%$ did not work in any paid job, $75 \%$ had income equal to their expenses, $94.6 \%$ had health insurance, $53.2 \%$ had one cesarean delivery and $26.9 \%$ were hospitalized twice.

In Table 2, the distribution of the mean scores obtained from the overall ICS-A and ICS-B dimensions of the Individualized Care Scale and their subscales, and the overall Newcastle Satisfaction with Nursing Scale was given. The mean scores the participating women obtained from the overall ICS-A and its Individuality in clinical situation, individuality in personal life situation and individuality in participating in decision making subscales were 3.50 $\pm 0.99,3.50 \pm 0.99,3.16 \pm 1.24$ and $3.50 \pm 1.03$ respectively. The mean scores the participating women obtained from the overall ICS-B and its Individuality in clinical situation, individuality in personal life situation and individuality in participating in decision making subscales were 3.82 $\pm 1.18,3.75 \pm 1.24,3.25 \pm 1.39,4.13 \pm 1.01$ and 70.53 \pm 16.27 respectively. 
Table 1. Descriptive Characteristics of the Women Having Undergone Cesarean Section

\begin{tabular}{lc}
\hline Variables & $\overline{\mathbf{X}} \pm$ SD \\
\hline Age & $\begin{array}{c}\text { Min-Max } 18-45 \\
\end{array}$ \\
\hline Educational status & $\mathbf{n}(\mathbf{\%})$ \\
\hline Primary school graduate & $\mathbf{6 9}(\mathbf{4 4 . 2})$ \\
High school graduate & $50(32.1)$ \\
University graduate & $37(23.7)$ \\
\hline Place of residence & \\
\hline Village & $28(17.9)$ \\
District & $34(21.8)$ \\
City & $\mathbf{9 4}(\mathbf{6 0 . 3})$ \\
\hline Economic status & $18(11.5)$ \\
Income less than expenses & $\mathbf{1 1 7}(\mathbf{7 5 . 0})$ \\
Income equal to expenses & $21(13.5)$ \\
Income more than expenses & \\
\hline Health insurance & $\mathbf{1 4 8}(\mathbf{9 4 . 9})$ \\
\hline Yes & $8(5.1)$ \\
No & \\
\hline Employment status & $33(21.2)$ \\
\hline Employed & $\mathbf{1 2 3}(\mathbf{7 8 . 8})$ \\
\hline Not employed & $\mathbf{8 3 ( 5 3 . 2 )}$ \\
\hline The number of Cesarean deliveries & $39(25.0)$ \\
\hline 1 & $34(21.8)$ \\
$\geq 3$ & $40(25.6)$ \\
\hline The number of hospitalizations & $\mathbf{4 2 ( 2 6 . 9 )}$ \\
\hline 1 & $41(26.3)$ \\
3 & $33(21.2)$ \\
\hline 4 &
\end{tabular}

Table 2. Mean scores obtained from the overall ICS-A and ICS-B dimensions of the Individualized Care Scale and their subscales, and the overall Newcastle Satisfaction with Nursing Scale (NSNS)

\begin{tabular}{l|c|c}
\multicolumn{1}{c|}{ Subscales } & $\overline{\mathbf{X}} \pm$ SD & Range \\
\hline ICS-A* & $3.50 \pm 0.99$ & $1-5$ \\
Individuality in clinical situation & $\mathbf{3 . 7 0} \pm \mathbf{1 . 0 6}$ & $1-5$ \\
Individuality in personal life situation & $3.16 \pm 1.24$ & $1-5$ \\
Individuality in participating in decision & $3.50 \pm 1.03$ & $1-5$ \\
making & & \\
& & \\
\hline ICS-B** & $3.82 \pm 1.18$ & $1-5$ \\
Individuality in clinical situation & $3.75 \pm 1.24$ & $1-5$ \\
Individuality in personal life situation & $3.25 \pm 1.39$ & $1-5$ \\
Individuality in participating in decision & $\mathbf{4 . 1 3} \pm \mathbf{1 . 0 1}$ & $1-5$ \\
making & & \\
\hline NSNS *** & $70.53 \pm 16.27$ & $0-100$
\end{tabular}

*Awareness of nursing interventions **Perception of individuality ***Newcastle Satisfaction with Nursing Scale

In Table 3, the correlation between the mean scores obtained from the ICS-A and ICS-B dimensions of the Individualized Care Scale (ICS) and the Newcastle Satisfaction with Nursing Scale was given. There was a significant, positive and high correlation between the mean scores the participating women obtained from the ICS-A and ICS-B dimensions of the Individualized Care Scale. On the other hand, the correlation between the mean scores obtained from the Individualized Care Scale and the
Newcastle Satisfaction with Nursing Scale was significant, positive and moderate.

Table 3. Correlation between the mean scores obtained from the ICS-A and ICS-B dimensions of the Individualized Care Scale (ICS) and the Newcastle Satisfaction with Nursing Scale (NSNS)

\begin{tabular}{|c|c|c|c|c|c|c|}
\hline Scales & \multicolumn{4}{|c|}{ ICS } & \multicolumn{2}{|c|}{ NSNS } \\
\hline & \multicolumn{2}{|c|}{ ICS-A } & \multicolumn{2}{|c|}{ ICS-B } & & \\
\hline & $\mathrm{r}$ & $p$ & $\mathrm{r}$ & $\mathrm{p}$ & $r$ & $\mathrm{p}$ \\
\hline $\begin{array}{c}\text { ICS- } \\
\text { A }\end{array}$ & -- & - & 0.832 & $0.001 *$ & 0.493 & $0.001 *$ \\
\hline ICS-B & 0.832 & $0.001^{*}$ & -- & -- & 0.490 & $0.001 *$ \\
\hline
\end{tabular}

In Table 4, the distribution and comparison of the introductory characteristics of women who gave birth by cesarean section and the mean scores obtained from the Individualized Care Scale and the Newcastle Satisfaction with Nursing Scale were given. As is seen in table 4, there was a statistically significant correlation between the economic status of the women and the mean scores they obtained from the scales ( $p$ <0.05). Of them, those whose income was more than their expenses were more satisfied with nursing care and their individualized care perception level was higher $(\mathrm{p}<0.05)$.

\section{Discussion}

Postpartum is a period when mother and baby need nursing care a lot (13). In this period, women's perception of individualized care is of great importance. In the present study, the mean scores obtained by the participating women who underwent cesarean section from the ICS-A related to awareness of nursing interventions aimed at supporting the individuality $(3.50 \pm 0.99)$ and ICS-B related to perceived individuality in the care given to them $(3.82$ \pm 1.18 ) were at a good level. In line with this result, we can say that the nurses were aware of individualized care and treatment needs of the patients and that the nursing care process was used appropriately, which was supported by the fact that the women who participated in our study were satisfied with nursing care. In the literature, although several studies in which patients' perception of individualized care was investigated by using the ICS were conducted (17-20), there is a gap regarding studies in which women's perception of individualized care was investigated. The findings of our study are consistent with those of studies conducted with different study groups. 
Table 4. Distribution and comparison of the mean scores obtained by the participating women from the ICS-A and ICSB dimensions of the Individualized Care Scale (ICS) and the Newcastle Satisfaction with Nursing Scale in terms of their descriptive characteristics

\begin{tabular}{|c|c|c|c|}
\hline & ICS-A & ICS-B & NSNS \\
\hline & $\overline{\mathbf{X}} \pm$ SD & M(Min-Max) & $\overline{\mathbf{X}} \pm$ SD \\
\hline \multicolumn{4}{|l|}{ Educational status } \\
\hline Primary school graduates $(n=69)$ & $3.52 \pm 1.06$ & $4(1-5)$ & $70.57 \pm 16.12$ \\
\hline High school graduates $(n=50)$ & $3.57 \pm 0.96$ & $4(1-5)$ & $71.18 \pm 14.74$ \\
\hline University graduates $(\mathrm{n}=37)$ & $3.38 \pm 0.90$ & $4(1-5)$ & $60.56 \pm 18.73$ \\
\hline Test significance value & $\mathrm{F}=0.415 \quad \mathrm{p}=0.661$ & $\mathrm{KW}=1.486 \quad \mathrm{p}=0.476$ & $\mathrm{~F}=0.104 \quad \mathrm{p}=0.902$ \\
\hline \multicolumn{4}{|l|}{ Place of residence } \\
\hline Village $(n=25)$ & $3.37 \pm 1.17$ & $4(1-5)$ & $65.07 \pm 19.31$ \\
\hline District $(\mathrm{n}=34)$ & $3.41 \pm 1.09$ & $4(1-5)$ & $78.08 \pm 11.77$ \\
\hline City $(n=94)$ & $3.57 \pm 0.88$ & $4(1-5)$ & $69.42 \pm 15.89$ \\
\hline Test significance value & $\mathrm{F}=0.637 \quad \mathrm{p}=0.530$ & $\mathrm{KW}=0.590 \quad \mathrm{p}=0.745$ & $\mathrm{~F}=5.798 \quad \mathbf{p}=\mathbf{0 . 0 0 4} *$ \\
\hline \multicolumn{4}{|l|}{ Economic status } \\
\hline Income less than expenses $(n=18)$ & $2.78 \pm 1.17$ & $3(1-5)$ & $63.94 \pm 17.59$ \\
\hline Income equal to expenses $(n=117)$ & $3.58 \pm 0.94$ & $4(1-5)$ & $70.08 \pm 15.63$ \\
\hline Income more than expenses $(n=21)$ & $3.69 \pm 0.84$ & $4(1-5)$ & $78.66 \pm 16.13$ \\
\hline Test significance value & $\mathrm{F}=5.788 \quad \mathrm{p}=\mathbf{0 . 0 0 4} *$ & $\mathrm{KW}=9.928 \quad \mathbf{p}=\mathbf{0 . 0 0 7} *$ & $\mathrm{~F}=4.321 \quad \mathbf{p}=\mathbf{0 . 0 1 5}$ * \\
\hline \multicolumn{4}{|l|}{ Health insurance } \\
\hline Yes $(n=148)$ & $3.50 \pm 0.97$ & $4(1-5)$ & $70.37 \pm 16.49$ \\
\hline No $(n=8)$ & $3.49 \pm 1.33$ & $4(1-5)$ & $73.37 \pm 11.89$ \\
\hline Test significance value & $\mathrm{t}=0.037 \mathrm{p}=0.971$ & $\mathrm{Z}=-0.244 \quad \mathrm{p}=0.807$ & $\mathrm{t}=0.506 \mathrm{p}=0.613$ \\
\hline \multicolumn{4}{|l|}{ Employment status } \\
\hline Employed $(n=33)$ & $3.58 \pm 0.72$ & $4(2-5)$ & $74.03 \pm 14.67$ \\
\hline Not employed $(n=123)$ & $3.48 \pm 1.05$ & $4(1-5)$ & $69.59 \pm 16.60$ \\
\hline Test significance value & $\mathrm{t}=0.494 \mathrm{p}=0.622$ & $\mathrm{Z}=-0.236 \quad \mathrm{p}=0.813$ & $\mathrm{t}=1.395 \mathrm{p}=0.165$ \\
\hline \multicolumn{4}{|l|}{ The number of cesarean deliveries } \\
\hline $1(\mathrm{n}=83)$ & $3.57 \pm 1.06$ & $4(1-5)$ & $70.78 \pm 18.78$ \\
\hline $2(n=39)$ & $3.44 \pm 0.89$ & $4(1-5)$ & $68.33 \pm 14.60$ \\
\hline$\geq 3(n=34)$ & $3.39 \pm 0.90$ & $4(1-5)$ & $72.44 \pm 12.90$ \\
\hline Test significance value & $\mathrm{F}=0.471 \quad \mathrm{p}=0.625$ & $\mathrm{KW}=0.461 \quad \mathrm{p}=0.794$ & $\mathrm{~F}=0.597 \quad \mathrm{p}=0.552$ \\
\hline \multicolumn{4}{|l|}{ The number of hospitalizations } \\
\hline $1(n=40)$ & $3.46 \pm 1.01$ & $4(1-5)$ & $68.12 \pm 20.74$ \\
\hline $2(n=42)$ & $3.57 \pm 0.93$ & $4(1-5)$ & $70.78 \pm 15.28$ \\
\hline $3(n=41)$ & $3.31 \pm 0.98$ & $4(1-5)$ & $69.53 \pm 12.42$ \\
\hline$\geq 4(n=33)$ & $3.70 \pm 1.03$ & $4(1-5)$ & $74.36 \pm 15.53$ \\
\hline Test significance value & $\mathrm{F}=1.046 \quad \mathrm{p}=0.374$ & $\mathrm{KW}=5.343 \quad \mathrm{p}=0.148$ & $\mathrm{~F}=0.955 \quad \mathrm{p}=0.415$ \\
\hline
\end{tabular}

Nurses are healthcare professionals who spend the most time with patients and are in closest contact with them (21). Therefore, nurses are the leading source for patients to obtain information and responses to their questions. In the literature, in studies in which satisfaction with nursing is evaluated, the mean scale score ranges between $67.82 \pm 16.13$ and $76.59 \pm$ $15.11(9,22-24)$. In the present study, the mean score regarding satisfaction with nursing was $70.53 \pm$ 16.27 , which suggests that the participating women who underwent cesarean section were generally satisfied with nursing care. In Bulut and Timur Tashan's, Karabulutlu and Yavuz's studies, nursing care satisfaction levels of women who underwent cesarean section were good too $(1,25)$. There are also several studies indicating that women were satisfied with nursing during their hospitalization after delivery $(26,27)$. The findings of the present study and those of the studies in the literature are similar, which indicates that the participants were satisfied with the nursing care. This situation can be explained by developing factors that increase satisfaction in the postpartum period, taking preventive measures for reducing factors, improving care policies, and continuing in-service training for nurses in recent years. On the other hand, the mean scores varied from one study to another, which may have stemmed from the differences between the health institutions where the studies were conducted, sample groups and the quality of health service. Although the satisfaction levels of the women in the present study were above average, it is noteworthy that these levels were well below the targeted level in nursing care.

The mean scores the participating women obtained from the subscales of the ICS-A were as follows: $3.70 \pm 1.06$ for the clinical situation, $3.1 \pm 1.24$ for the personal life situation, and $3.50 \pm 1.03$ for participating in decision making about care. These results indicate that individuality is more noticed in nursing activities in clinical situations. This suggests that the patients perceived individuality in nursing 
practices more when there was deterioration in their clinical condition.

The mean scores the participating women obtained from the subscales of the ICS-B were as follows: $3.75 \pm 1.24$ for the clinical situation, $3.25 \pm 1.39$ for the personal life situation, and $4.13 \pm 1.01$ for participating in decision making about care. This result indicates that the clinical characteristics of the women were taken into account while they were given care, and that their participation in decision making about care was ensured, but that the least considered factor was their characteristics related to their personal life situation. Within this context, it can be said that the factor regarding patients' personal life situation should be improved. The study results of Ogut and Uyar Hazar support our findings (20). On the contrary, Abdelati et al. found that women who underwent cesarean section were not satisfied with their decision-making processes in participating in their care (28).

In the present study, no statistically significant correlation was determined between the variables such as the women's educational status, place of residence, having health insurance, employment status, the number of cesarean births and the number of hospitalizations, and their levels of individualized care perception and nursing care satisfaction. This result is consistent with those of the studies conducted by Ceylan and Eser, Ogut and Uyar Hazar, Kaya and Vural $(17,20,29)$. Contrary to the findings of our study, in some studies, individual characteristics negatively affected the perception of care and satisfaction with nursing care $(30,31)$. However, Singla et al. reported that there is no statistically significant relationship between educational status and the level of satisfaction with postpartum nursing care (32). These findings suggest that the women's socio-demographic characteristics did not affect the evaluation of nursing services in the early postpartum period.

The results obtained in the present study indicate that there was a statistically significant correlation between the place of residence and the level of satisfaction with nursing, and that satisfaction levels of the women whose place of residence was the district were higher than were of those the women whose place of residence was the city center or villages. This result is consistent with that of Sise's study (12) but different from that of Temizyurek Yavuz and Basaran Ac1l's study (31). This suggests that patients' expectations of nursing services were affected by their place of residence.

In the present study, a statistically significant correlation was determined between the economic status of the participants and the mean scores they obtained from the scales. Participants whose income was higher than their expenses were more satisfied with nursing care and their perception of individualized care was higher than those with lower expenses. In the literature, there are studies whose results support this finding $(31,33)$. This suggests that the expectations of women with good income may decrease because they themselves can meet most of their needs in the hospital.

A patient's previous experiences and information obtained from external sources can affect their expectations of healthcare professionals responsible for their treatment and care (34). In the present study, the correlation between the previous hospitalization status of women who had cesarean delivery and their satisfaction with nursing care was not statistically significant ( $p>0.05$; Table 4). The results of studies conducted by Sise and Ogut and Uyar Hazar are consistent with our findings $(12,20)$. This result can be explained by the fact that the number of the women who had only one hospitalization experience was high. However, it also suggests that the hospitalization of women with more than one previous hospitalization experience did not affect their perception and satisfaction with nursing care, because their expectations of nursing care were the same each time they were hospitalized.

In the present study, the number of cesarean deliveries had no effect on the participants' perception of individualized care and nursing care satisfaction. Although our search for studies in which the relationship between the perception of individualized care and cesarean section was investigated demonstrated a gap in the literature, in their study, Ogut and Uyar Hazar (20) stated that women's levels of perception of individuality in the care given to them (ICS-B) decreased significantly as the number of births they gave increased. In the literature, there are several studies conducted on the effect of the number of cesarean deliveries on the satisfaction with nursing care whose results support the findings of our study. For instance, no significant correlation was determined between the number of pregnancies and satisfaction with nursing care in Christiaens and Bracke's study and between the number of cesarean deliveries and satisfaction with nursing care in Kaya and Vural's study ( $p>0.05)$ $(29,35)$. These results in our study can be explained by the fact that the number of women who had only one cesarean delivery was high. In addition, it can be said that previous birth history did not affect current individualized care perception and satisfaction with nursing care. 
In the present study, a strong positive correlation was determined between the level of satisfaction with nursing care and the mean scores obtained from the ICS-A and ICS-B. As the patients' awareness of nursing activities increased, so did their perception of individuality in the care given to them and their satisfaction with nursing. A moderate positive correlation was determined between perception of individuality in the patients' own care, and awareness of nursing activities and satisfaction with nursing care. In the present study, it was observed that as the patients' level of perception of individualized care increased, so did their levels of awareness of nursing activities and their satisfaction with nursing care. In the literature, there is a gap related to studies in which the relationship between perception of individualized care and satisfaction with nursing care among women who underwent cesarean section was investigated. However, in Ogut and Uyar Hazar's, a positive relationship was found between women's perception of individuality in their postpartum self-care and satisfaction with midwifery care (20). A positive relationship was determined between perception of individualized care and satisfaction with nursing care in patients in Acaroglu et al.'s study, and in patients who underwent orthopedic surgery in Tekin and Yildiz Findik's study $(36,37)$. The results of both studies were consistent with those of our study. Snyder and Engstrom stated in their study that the results of patient participation were patient satisfaction, health care cost and health care outcomes (38). Similarly, Prey et al. stated that satisfaction with nursing care and patient participation were related, but there were deficiencies in practice, and patient participation was inadequate (39). In Tambuyzer et al.'s study, a statistically significant relationship was determined between patient participation and satisfaction (40). As determined by Abdelati et al., women who underwent cesarean section were not satisfied with the psychological care, continuity of care, and participation in decision-making processes in the provision of care (28). All these suggest that there is a need for regulations aimed at encouraging patient participation in the provision of care and increasing patients' satisfaction with nursing.

\section{Conclusion}

It was determined that the women who underwent cesarean section had a good level of perception of individualized care and satisfaction with nursing. As the rate of awareness of nursing activities among the participants increased, so did their perception of individuality in the care given to them and, as the patients' awareness of nursing activities and the level of individuality in perceiving nursing care increased, so did the rate of satisfaction with nursing care. It can be said that the satisfaction of women who had cesarean delivery with nursing care is influenced more not by their demographic characteristics but by whether their care needs are met. Although participation in patient care is a mutual relationship, our study reveals only patient views. Therefore, it is recommended that in future studies, not only the opinions of patients who receive care from nurses but also those of nurses who give care to patients regarding patient participation should be investigated.

Ethics Committee Approval: Ethics committee approval was received for this study from Sivas Cumhuriyet University Clinical Research Ethics Committee (Ethics Committee Date and no: 2018-04 / 02)

Peer-review: Externally peer-reviewed.

\section{Author Contributions:}

Concept: E.Y, N.T, Design: E.Y, N.T, Literature Search: E.Y, N.T, Data Collection and Processing: E.Y, Analysis or Interpretation: E.Y, N.T, Writing: E.Y, N.T.

Conflict of Interest: No conflict of interest was declared by the authors.

Financial Disclosure: The authors declared that this study hasn't received no financial support.

\section{References}

1. Bulut H, Tashan ST. Determination of Levels of Satisfaction Nursing Care of Women with Cesarean Section. Inonu University Journal of Health Sciences 2017;6(1):1-6.

2. Gozukara F, Eroglu K. A Way to Prevent the Increase in Cesarean Birth: Vaginal Birth After Cesarean Instead of "Once a Cesarean Always a Cesarean" Approach and the Roles of Nurse. Faculty of Health Sciences Journal of Nursing 2011;18(2):89-100. https://dergipark.org.tr/tr/pub/hunhemsire/issue/7 $837 / 103244$

3. Izbizky G, Minig, L, Sebastiani M. Otaño L. The effect of early versus delayed postcesarean feeding on women's satisfaction: a randomised controlled trial. BJOG 2008; 115: 332-338.

4. Baskaya Y, Sayiner FD. Evidence-Based Midwifery Practices to Reduce Cesarean Rate. HSP 2018;5(1):113-119. doi: $10.17681 / \mathrm{hsp} .335472$. 
5. Yanikkerem E, Cimen E. Delivery methods of nurses and perspectives on vaginal delivery after cesarean. MCBU- Journal of Health Sciences Institute 2017;4(1):533-541.

6. Celik AS, Turkoglu N, Pasinlioglu T. Determining the postpartum life quality of mothers. Anatolian Journal of Nursing and Health Sciences 2014;17(3):151-157.

7. Bagci S, Altintug K. Problems experienced by mothers in postpartum period and their associations with quality of life. Journal of Human Sciences doi:10.14687/jhs.v13i2.3884.

8. Ceylan B. Individualized care in nursing. Ege University Journal of Nursing Faculty 2014; 30(3): 59-67.

9. Tugut N, Golbasi Z. Nursing Service Satisfaction Level of Patients At Gynecology And Obstetrics Unit of A University Hospital And Some Affecting Factors. Journal of Education and Research in Nursing 2013; 10(2):38-44.

10.Kayrakci F, Ozsaker E. Determination of The Surgical Patients' Saticfaction Levels from Nursing Care. FNNJ 2014; 22(2): 105-113. doi:10.17672/fnhd.64060.

11.Akin S, Erdogan S. The Turkish version of the Newcastle satisfaction with nursing care used on medical and surgical patients. Journal of Clinical Nursing 2007; 16(4): 646-653. doi: 10.1111/j.1365-2702.2006.01583.x.

12. Sise S. Patient satisfaction with nursing services. Kocatepe Medical Journal 2013; 14(2): 69-75.

13. Simsek C, Esencan TY. Nursing Care During the Postpartum Period. Zeynep Kamil Medical Bulletin 2017; 48(4): 183-189. doi: http://dx.doi.org/10.16948/zktipb.267263.

14.Suhonen R, Leino-Kilpi H, Valimaki $M$. Development and psyhometric properties of the individualized care scale. Journal of Evaluation in Clinical Practice 2005;11(1): 7-10.

15.Acaroglu R, Sendir M. The Scales for Assessment of Individualized Care. IUFNNJ 2012;20(1):1016.

16.Thomas LH, McColl E, Priest J, Bond S, Boys RJ. Newcastle satisfaction with nursing scales: an instrument for quality assessments of nursing care. Quality in Health Care 1996; 5:67-72.
17.Ceylan B, Eser I. Assessment of individualized nursing care in hospitalized patients in a university hospital in Turkey. Journal of Nursing Management 2016;24(7): 954-61. doi: 10.1111/jonm. 12400 .

18.Rasooli AS, Zamanzadeh V, Rahmani A, Shahbazpoor M. Patients' point of view about nurses' support of individualized nursing care in training hospitals affiliated with Tabriz University of Medical Sciences. Journal of Caring Sciences 2013;2(3):203-209. doi: $10.5681 /$ jcs.2013.025.

19. Alici CB, Koc Z. Quality of life and satisfaction affect individualized nursing care perceptions in intensive care. Psychology, Health \& Medicine 2020; 25(2): 148-159.

20.Ogut D., Uyar Hazar H. Women's perception and satisfaction levels of postpartum individualized care. Aydin Adnan Menderes University Institute of Health Sciences Master's Thesis, 2019.

21.Celik Durmus S, Yildirim A. Cooperation between nurses. Journal of Health and Nursing Management 2018;5(3):210-216. doi:10.5222/SHYD.2018.210.

22.Ulgen T, Zeybekci S, Ugur O. Hospitals on a University Hospital Oncology Clinic Nursing Satisfaction and Affecting of Effective Variables. Turkiye Clinics J Nurs Sci 2018; 10(1):18-27. doi: 10.5336/nurses.2017-56254.

23. Yanik S, Ates S. Identification of nursing care satisfaction levels and relatied factors of inpatients at internal medcine clinics. International Refereed Journal of Nursing Research 2018;14,24-43. doi:10.17371/UHD.2018.3.7

24.Kersu O, Mert Boga S, Kosgeroglu N, Aydin Sayilan A, İlter G, Baydemir C. Determination of The Relationship Between Perception of Nursing Quality and Satisfaction Status of Patiens Hospitalized in Surgical Services. Journal of Education and Research in Nursing 2020; 17(1): 32-39. doi:10.5222/HEAD.2020.032

25. Karabulutlu O, Yavuz C. Evaluation of Satisfaction Levels of Mothers' Midwifery/Nursing Care Given in The Postpartum Period. Caucasian Journal of Science 2019;6(2):182-199. https://dergipark.org.tr/tr/pub/cjo/issue/51152/63 3149. 
26. Arslan Gurcuoglu E, Vural G. Satisfaction of Mothers with Midwifery/Nursing Care Given in the Postpartum Period in Hospital. Gazi Medical Journal 2018;29(1):34-40.

27.Pinar G, Dogan, N, Algier L, Kaya N, Cakmak F. Factors that affecting mothers' postnatal comfort. Dicle Medical Journal 2009;36(3):184-190.

28. Abdelati, IH, Saadoon Om Hashim M, Ahmed Mostafa Amal R. Quality of cesarean section nursing care and its reflection up-on women's satisfaction with labor experience. International Journal of Advanced Nursing Studies 2019;8(1):11-18. doi: 10.14419/ijans.v8i1.27149

29. Kaya A, Vural G. Mothers hospitalized in the post-cesarean delivery service to determine the level of satisfaction with the nursing care they receive. Selcuk University Institute of Health Sciences Master's Thesis, 2011.

30.Lee HJ, Jang SG, Choi JE, Lee W, Pyo J, Ock M, et al. Assessment of Public Perception Regarding Patient Engagement for Patient Safety in Korea. Journal of Patient Safety 2021;17(1):44-50. doi: 10.1097/PTS.0000000000000565.

31.Temizyurek Yavuz M, Basaran Acil S. Examination of the patients' participation in nursing care and their satisfaction with nursing. Hacettepe University Institute of Health Sciences. Master's Thesis. 2019.

32. Singla N, Mamta Taneja A, Kaur J. Study on Satisfaction Regarding Intrapartum and postpartum Nursing Care among Women. International Journal of Current Research 2015;7(3):13373-13375.

33. Coban Gİ, Kasikci M. Validity and reliability study of the scale of the patient's perception of nursing care Ataturk University Institute of Health Sciences. Master's Thesis. 2006.

34.Alan H. Patient Satisfaction with the Nursing Services in a University Hospital. Journal of Education and Research in Nursing 2018; 15(2): 81-87.

35. Christiaens W, Bracke P. Place of birth and satisfaction with childbirth in Belgium and the Netherlands. Midwifery 2009;25(2):11-19. doi: 10.1016/j.midw.2007.02.001.

36.Acaroglu R, Sendir M., Kaya H, Sosyal E. The Effect of Individualized Nursing Care on the Patient Satisfaction and Quality of Life. Florence Nightingale Journal of Nursing 2007;15(59):6167.
37.Tekin F, Yildiz Findik U. Level of Perception of individualized care and satisfaction with nursing in orthopaedic surgery patients. Orthopaedic Nursing 2015;34(6):371-374. doi: 10.1097/NOR.0000000000000194.

38. Snyder H, Engstrom J. The antecedents, forms and consequences of patient involvement: A narrative review of the literature. International Journal of Nursing Studie 2016; 53:351-378 doi: 10.1016/j.ijnurstu.2015.09.008.

39.Prey JE, Woollen J, Wilcox L, Sackeim AD, Hripcsak G, Bakken S, et al. Patient engagement in the inpatient setting: a systematic review. Journal of the American Medical Informatics Association 2013; 21(4): 742-750. doi: 10.1136/amiajnl-2013-002141.

40.Tambuyzer E, Van Audenhove C. Is perceived patient involvement in mental health care associated with satisfaction and empowerment? Health Expectations 2015;18(4):516-526. doi: 10.1111/hex.12052. 